abandoned him to his fate. Though convinced of the necessity of lithotumy, the absence of the proper instruments for its performance decided me not to resort to any improvised plan, as a fatal issue would be adverse to my reputation, while recovers would be more valuable to the cause of European medicine than an unlimited number of cures effected by the doubtful aid of drugs.

Opium and nitric acid were prescribed, the effect of which I did not see, as I was obliged to leave for Bhamo in a few days. On my return, however, I found him in the same state, when I wrote to the Civil Surgeon at Thyet-Myo, for a grooved staff, when he kindly sent me his lithotomy case; but, in the interval, the patient had returned to his village about 20 miles distant, and though I took steps to induce him to return, I began to despair of his doing so, and sent back the instruments to Thyet-Myo.

In a few days, much to my surprise, he again appeared. Now I determined to cut him at all hazards, and, to supply the place of a grooved staff, filed away about five inches of the convex surface of a grooved catheter, so as to enter its hollow canal, thus forming a groove for the guidance of the knife towards the bladder.

On the following day, with the aid of my own servants and several of Rev. Mr. Marks' schoolboys, I introduced the catheter, tied him in position, administered chloroform, cut down on the catheter with a sharp scalpel, introduced my finger, at the same time dividing any constricting bands with a probe-pointed bistoury as in the operation for herniafollowing, in fact, the combined cutting and tearing method introduced and successfully practised by Liston. On feeling the strod the forceps introduced, and after some traction an oblong fawn-colored, laminated, friable stone of the triple phospate, was, to the surprise of the Burmese, brought to light.

The stone weighs 2 ounces; is $2 \frac{1}{2}$ inches long, and $1 \frac{1}{4}$ in diameter. Quinia and laudanum with a little brandy were given, and a weak solution of carbolic acid applied to the wound, no plug or tube being at any time introduced.

The patient was again removed to the Rev. Mr. Marks' coach house, when the sohoolboys attended to his wants (there is neither hospital or medical subordinate attached to the Residency): he recovered without a bad symptom, and has since been several times to Mandalay with his relations, bringing little presents of fruit and corn as expressions of their gratitudea virtue a greater store of which the Burmese possess than any people with whom I have come in contact.

This man states that he knew of four men to die of his disease in or about his own village, the prevalence of which I can only attribute to vegetable and perhaps insufficient food. The drinking water has, I believe, nothing to do with its causation, as it is the river water, used by all the villages along its banks.

The hills above the village are composed of clay slate intermixed with limestone strata.

Remarks. - In the absence of all surgical knowledge, the Burans - In their Indian brethren, who, I have heard, are not only expert lithotomists, but also perform have henrd, are not onfy exper operations skilfully. And this is all the more remarkable as all their medical literature is of Sanscrit and Indian origin, and I have heard from intelligent natives that some surgical books Thave heard from intellig menares in the time of the Hindoo Emperor Dhununterry, who lived contemporary with our deluge or the books must have or thereabouts. Ifferent civil wars and invasions that devastated perished in the different civil wars and invastory. However great their former knowledge may have been, there is at present then of it remaining, for the surgeon even in the old and lowest rone of it remaining, for the surgeon even not exist. There is not the faintest knowledge of anatomy amongst those who in any way practice the healing art. They use no knife or instrument of any practice the healing art. They use no knife fact all acquired and coft to nature, even abscesses are never opened. Amputation is not performed unless as a punishnever opened. Amputation is not performer has been the active ment, and then only when the member has been the active and boiling oil are called into requisition-in fact a mode of operation practised prettr generally in Europe antecedent to the term of Ambrose Paré. They are equally in ignorance as regards the obstetric art, though I have seen rude books and other midwifery instruments in India. The patients are as reluctant to submit to, as the doctors are to practice, surgery ; even when the operation is simple, and obviously necessary, the greatest tact is required; the most favourable time being generally at the first consultation, before they have leisure, to become influenced by the advice of their friends. From all this it must not be imagined they are equally ignorant of medicine. On the contrary, they have many useful medicines, and sundry learned themes; the phrsicians are numerous, and practise medicine with a good deal of success. For instance, their treatment of leprosy with petroleum, which exists in abundance in the country, is said to be very 'successful, and the use of the cold bath in the hot stage of fever has long been known amongst them.

Mandalay, 1st May 1875.

\section{CASE OF EMPYEMA.}

By J. Stane, L.R.c.P., Civil Medical Officer, Goalpara.

I am induced to send you the following case, as it would seem to indicate that a departure from the usual practice of tapping the chest in empyema "between the fifth and sixth ribs, a little behind their middle," may prove advantageous in some cases.

Ramlall, a young native from Behar, in the service of the Raja of Bijnee, was admitted to the Goalpara charitable dispensary on the 28th February last in a very feeble state, suffering from a frequent cough, dyspnoen, and diffused pain in the left side of the chest. He stated that, about a fortnight before, he had been attacked by cholera, and had been attended by the Raja's Native Doctor, who, however, left him imperfectly cured, (bemurumthes was the expression used), and that he had been (bemurumthoe was the expression fever, with severe pain in the left side of the chest. He was a good deal emaciated, and his features had an expression of alarm attributable to the dyspnoea which was urgent. The left side of the chest was much increas in size, two inches in excess of the measurement of the opposite side, and the intercostal spaces were effaced. The respiratory murmur was scarcely audible over the side, the percussion sound was excessively dull, and the heart was displaced to the midale of sternum towards the right side. The right lung gave the usual signs of complementary action. An exploring needle was introduced between the fifth and sixth exploring neede was little pus welled up, and, as asphyxia appeared imminent, immediate tapping was resolved on, and performed with a small hydrocele trocar and canula in the performed before mentioned; the skin having been raised in a situation before mentioned trocar was pushed into the pleural valvular fold befority ounces of pus of a laudable character cavity. About thirt with evident relief to the patient. A strip of adhesive plaster was then applied to the puncture, and a of adhesive plaster was then chest. Next day he was able to sit broat but the bandage was saturated with discharge which had up. but the bandage was a very suspicious swelling in the flnwed from the chest, anoticed, and afterwards proved to be pus, infra-axillary region was noticed, and afterwards proved the valve the escape it had gravitated to this situation. An incision was made into the swelling, and the pus evacuated. But a fresh accumulation took place in the pleural cavity, and the a fresh a performed on the 10 th day from the first operation, and about fourteen ounces of pus, of a slightly fotid odour, was withdrawn. A drainage tube was now introduced, and the pleural sac syringed out daily with a weak lotion of Condy's fluid, two drams to a pint of water, but although a free discharge was established evidence was soon although a free frection acculation of a very acrid character for the patient now suffered from irritative fever, and began to shew signs of exhaustion. On the fourth day, therefore, from the second operation, I made an opening posteriorly in the 9th intercostal space, and evacuated about twenty-four ounces of very foetid pus; the opening was enlarged with the bistoury, very fotia pus; the cusul attempts to pass a drainage tube and after several unsuccessful attempts to paser opening by means from the superior aperture through the lower was owing to the of a bent gun-shot probe, which probing band of lymph, I probe being opposed by some with introducing through the latter was fain to content myself with introducing diameter of a gaose about six ounces of drain the pleural cavity was daily syringed quill, through which the pleu, or the lotion of Condy's fluid with a weak carbolic No improvement however ensued, though above-mentioned. No improvement how, and my patient died the dyspnœa was arter the last operation.*

In conclusion, I may observe that the operaticn of paracentesis thoracis could not be performed so low down on the right side,

- I proposed a post-mortem examination to the friends, but they would not consent to it, and hurried the body away for cremation. 
owing to the liver being so much higher placed than the spleen; but still I believe it could be performed much lower than between the fifth and sixth ribs, as the effusion if in any quantity would push the liver downwards and admit of a lower position for puncture being taken up. Of course the possession of a Bowditch's syringe would altogether do away with the necessity for this operation, but at dispensaries the trocar and canula must still be used.

Goalpara, 29th May 1875.

\section{dotices to cortespondents.}

It is particularly requested that all contributions to the "Indian Medical Gazette" may be written as legibly as possible, and only ON ONB SIDB of eacin sineet of paper.

Technical expressions ought to be so distinct that no possible mistake can be made in printing them.

Neglect of these simpie ruies causes much trouble.

Communications sinould be forwarded as early in the month as possible, else deiay must inevituobly occur in their publication.

Business letters to be forvarded to the Publishers, Mrssis. Wran \& Co., and all professional communications to the Editor, direct.

\section{Communications have been received from-}

Surgeon T. MAтNE, 2nd M. N. I.; J. SLANE, L.R.C.P., Civil Medical Officer, Goalpara; Surgeon D. H. CuLlmoв E, Resident Surgeon, Mandalay; Surgeon-Major C. R. G. PARKER, Vizianagram; Surgeon R. HARVBY, M.B, Bengal Medical Service; Surgeon H. W. HiLL, M.B., Civil, Pooree; Assistant-Apothecary JoNks, General Hospital, Madras; Surgeon-Major J. DAvis, A.M.D.; Surgeon H. A. CHatha

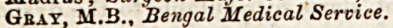

\section{Adthrowledgunents.}

The Lancet, Nos. 16 to 19 of Vol. I of 1875; The British Medical Journal, Nos. 746 to 749; The Medical Times and Gazette, Nos. 1294 to 1297; The Medical Press and Oircular, Nos. 1888 to 1891; The Phi ladelphia Medical Times, Nos. 173 to 178; Gazette Medicale de Paris, Nos. 12 to 20 ; The Edinburgh Medical'Journal, May; The New York Medical Journal March and April; The Canada Medical and Surgical Journal, April; The Argus, (Melbourne) March 30th, April 24th, and May 5th; The Age (MIelbourne) March 27th; The Mel bourne Medical Record, Nos. 5, 8, 7 and 8, of Vol. IV; Report (Sup bourne Medical Record, Nos. 5, Skin Disease observed in the Madras

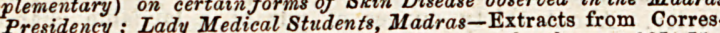
pondence; Report of the Aboo Lawrence Asylum for the year 1874-75.

\section{The Endian Atedical Gašctte.}

\author{
JULY 1, 1875.
}

\section{OVERWORK}

There is no subject in the whole range of sanitary science, in which it is so difficult to lay down positive rules of general application, as mental hygiene. The difficulty arises from the very great differences which exist among men in respect of mental endowments and faculties, and in regard to mental powier and endurance. All men are differently gifted hereditarily and congenitally in intellect and emotion, and they present diversities in mental physiognomy just as remarkable as in configuration, feature and expression. Education, embracing in the term every influence which conditions the plastic and growing mind, is as varied as are the circumstances in which men develope, and enhances or modifies congenital idiosyncrasies. Finally, the circumstances and surroundings of the developed and educated human being, each and all of which exercise some influence on his mental life, present an infinite variation. The mental outcomings of an adult man are the resultant of a vast aggregate of forces, which, differing in kind, degree, and combination in different individuals, are not only co-extensive in time and space with his own period of life and sphere of activity, but stretch back to times and ways of his ancestry. Every man is thus the focus, as it were, of an infinitely numerous and complex convergence of influences, the analysing of which offers perhaps the most difficult problem which it is possible to contemplate. Were it practicable to construct or imagine a typical being, and place him in typical circumstances, then it might also be possible to lay down typical rules for his guidance, to the end that he should, under such circumstances, perform the greatest possible amount of men. tal work in the best possible way and with the least possible damage to his health ; but an attempt of this sort would only rield a Utopia or a Laputa. Is then the hope of formulating general rules for mental health and exercise a vain one? We should not dismiss this question by a plump negative, for men and their lifecircumstances can be inductively distributed into certain broad classes, in which certain methods and rules of living are by experience found to be beneficial or the reverse; but it must always be remembered that broad rules of this kind, when it is attempted to apply them to individuals, must be used with a full view to the individual peculiarities and idiosyncrasies by whose exclusion they have been alone rendered possible. These principles will, we doubt not, command ready assent; but readers, who may, perbaps, have quailed somewhat at the picture of the symptoms and consequences of mental overwork drawn in our last, recognizing in their own experience some of the former and dreading the latter, will not be content with platitudes. The questions which we have committed ourselves to answer, would, in the mouths of such "anxious inquirers," take some such shape as the following. How should a man order his life and habits, so as to, on the one hand, exact from his brain all the work of which it is capable, without, on the other, impairing its energy and tone, or injuring its health? How many hours should an averagely healthy man be able to devote to sound brain work without risk? How far does this standard require modification according to climate, season, and bodily heaith ? How many hours should be devoted to sleep in order to conserve brain vigour? What of diet, stimulants, exercise, amusements? How often is it necessary to take a holiday, snort or prolonged? And, when signs of overwork manifest themselves, what is to be done? These questions do not admit, for the reasons above stated, of very definite reply, but we shall jot down a few observations on each of them. As regards the number of hours which ought to be devoted to work, this will depend much on the kind of work and the way of working, in otker words, on the extent to which the work done taxes the attention, and strains the mind. A few hours of composition, for instance, are more wearing than a whole day devoted to routine and signing one's name; the hearing of a case in which perhaps the evidence is contradictory and lying, is infinitely harder work than the dilettante stuciy of the contents of a box containing a lot of light buiklles; the performance of a surgical operation, the delivery of an extempore lecture, or attendance on a serious case, involves more strain and wear, than hours of reading or routine practice; one man addresses himself to work with eagerness and concentration, another saunters and dawdles through his daily task. How then, with these great differences of men and their pursuits, is it possible to prescribe a hard rule? We believe that from 6 to 8 hours of really hard, honest, mental labour is as much as an average man can properly perform in this country. We hear of men working from 10 to 12 or even 14 hours a day, but the process must, we are convinced, be nothing more than a quiet simmering of sluggish thought, for if the mind be kept at the boil for so 